\title{
Assessment of the impact of selected changes in the deep geological repository model on its long-term safety
}

\author{
Dorota Flamíková \\ Slovak University of Technology in Bratislava, \\ Institute of Nuclear and Physical Engineering \\ Bratislava, Slovakia \\ dorota.flamikova@stuba.sk
}

\author{
Vladimír Nečas \\ Slovak University of Technology in Bratislava, \\ Institute of Nuclear and Physical Engineering \\ Bratislava, Slovakia \\ vladimir.necas@stuba.sk
}

\begin{abstract}
The deep geological repository system provides long-term protection against the undesirable effects of ionizing radiation on the population and the environment. An important part of the long-term safety strategy is development of a monitoring program that collects information about the behaviour of the deep geological repository throughout its whole lifetime. A simplified model of the disposal system, geosphere, and biosphere was developed using the GoldSim simulation tool to demonstrate the behaviour of the hypothetical deep geological repository located in crystalline rocks. Also an initial model of the reference biosphere was created based on the scenario of an agricultural habitation (normal evolution scenario) and it was developed based on the recommendations provided in the BIOMASS methodology. After a significant period of time, disposal containers will be degraded and evolution changes in the repository system will occur. Several important parameters appear in the annual effective dose calculation for an individual from critical exposure group within the reference biosphere model. One of them are, for example, distribution coefficients and so-called translocation factors that define the transported rate of released radionuclides into the environment. This paper provides a view into the selected part of the deep geological repository through the data obtained by monitoring during the selected period of time. Simulations describing changes in the repository system. The aim of this contribution is to evaluate the impact of selected changes on the annual effective dose for an adult individual from a critical exposure group while it is assumed, that the respondent consumes contaminated crops and animal products. This model includes various biosphere components and multiple exposure pathways such as inhalation, ingestion and external exposure.
\end{abstract}

Keywords - deep geological repository, biosphere model, annual effective dose, GoldSim, long-term safety

\section{INTRODUCTION}

The disposal of spent nuclear fuel and other highly radioactive waste originating mainly in the nuclear energy sector is a topic with huge social importance. The basic requirement of repositories for radioactive waste is the prevention of the leakage of radionuclides into the biosphere. The safe disposal of

This contribution has been partially supported by the Slovak Grant Agency for Science through grant VEGA 1/0863/17 and by the Slovak Research and Development Agency through grant APVV-15-0558. spent nuclear fuel in deep geological repositories (DGR) is based on the so-called multi-barrier concept. In order to evaluate the long-term safety of the deep repository, a comprehensive model of the reference biosphere, geosphere and disposal system should be created to obtain information on radionuclide migration in a given environment, radiation load, etc. The model serves as a tool for calculation of the annual effective dose for the individual representative from the critical exposure group caused by radionuclides released into the environment.

\section{MONITORING OF THE DEEP GEOLOGICAL REPOSITORY}

Geological repositories for the disposal of high level radioactive waste and spent nuclear fuel are designed to provide isolation of these type of waste from the population and environment for many thousands of years.

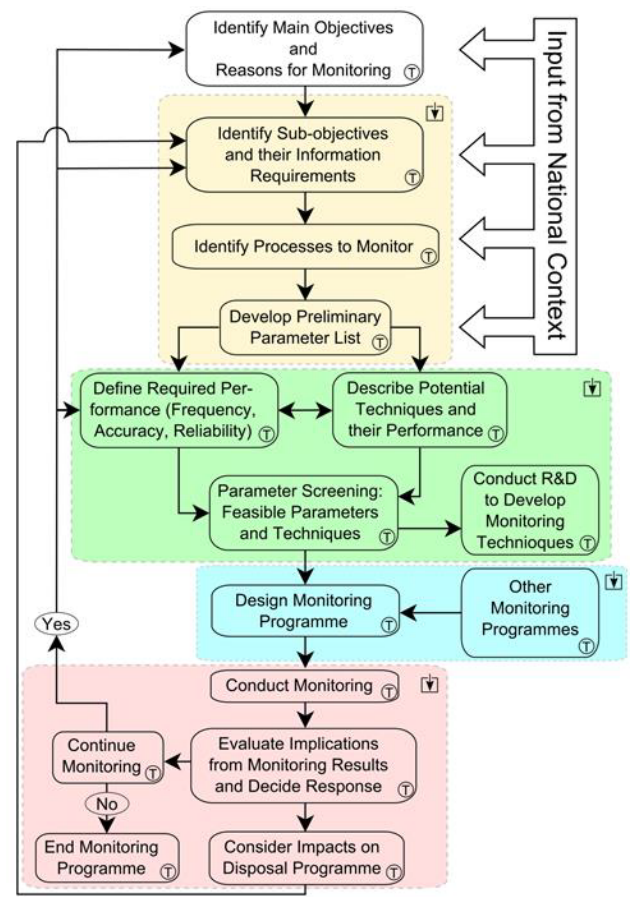

Fig. 1. Structural approach of the DGR monitoring process [1]. 
Monitoring the environment of such repositories is not therefore expected to reveal any increase of radioactivity due to the repository, it is planned and intended for other purposes. These include providing reassurance that the repository is fulfilling its intended purpose, but there can be other reasons of a technical nature.

Monitoring is expected to play an important role in both development and execution of geological disposal programmes. In particular, monitoring will contribute essential information for the satisfactory completion of the various phases of the geological repository programme and, in doing so, will strengthen confidence in long-term safety, which is the key objective of radioactive waste disposal. The example of an structural approach of the monitoring programme of deep geological repository shows Fig. 1. For the purpose of the present paper the following definition of monitoring has been employed: continuous or periodic observations and measurements of engineering, environmental or radiological parameters, to help evaluate the behaviour of components of the repository system, or the impacts of the repository and its operation on the environment. The process leading to the commissioning of geological disposal facilities for long lived radioactive waste is quite lengthy and involves a number of decision points. Once authorized to operate the facilities are expected to remain in activity for long periods of time before their eventual decommissioning and closure. Monitoring of various aspects of the disposal system is likely to be an important support to decision-making at all stages of the repository development programme. After closure, the long term safety of geological disposal facilities, due to the duration of the hazard associated with the waste, cannot rely on institutional controls, including monitoring. However, continuing monitoring is likely to be a societal demand for some time after repository closure. Such monitoring, besides showing that the process of decommissioning surface facilities has been successfully completed, would also strengthen the confidence, at least in some sectors of society, that the evolution of the waste isolation system is in accordance with expectations. The need to safeguard nuclear materials contained in the repository may also cause some form of monitoring or surveillance to continue in the post closure phase.

\section{Using of monitoring information}

Certain monitoring activities should begin at the earliest possible time within a repository development programme, before the perturbations caused by repository construction and operation begin to accumulate. This early information is important because it allows an understanding to be developed of the nature and properties of the natural, 'undisturbed' environment of the disposal system. Parameters obtained from monitoring process will be used for example to evaluate changes that occur in the rock and groundwater system during the construction and operational stages and, in the post-closure period, to evaluate any impacts that the presence of the repository may have on natural processes and the environment. In practice, the monitoring programme will begin during the site investigation stage. The characteristics of primary interest in the context of establishing baseline information are [2]:

- the groundwater flow field in the host rock and in the surrounding geological environment (groundwater pressure distributions, hydraulic gradients, regions of recharge and discharge, etc.);

- geochemical characteristics of groundwater (redox, salinity, major and trace element concentrations, natural radionuclide content, etc.);

- levels of radioactivity in groundwater, surface waters, air, soils and sediments, animal and plant life;

- meteorological and climatic conditions;

- hydrology of surface water systems, including drainage patterns and infiltration rates;

- ecology of natural habitats and ecosystems.

Baseline data should be established as part of the site characterisation activity, e.g. measurements from local and regional boreholes and surface investigations. Where important parameter values are found to follow an increasing or decreasing trend, baseline monitoring will need to be continued until that trend is established with confidence and the reasons for the trend are sufficiently well understood. The establishment of baseline values for surface environmental indicators is relatively straightforward, because the process of measurement will, in general, not affect the parameters being measured. However, it is to be appreciated that invasive investigations will themselves perturb the natural groundwater system to a degree based on site specific conditions. In order to establish baseline conditions with which to judge later impacts, e.g. changes to groundwater pressures and hydro-chemical conditions in response to repository construction, sufficient information needs to be collected in the surface exploration phase to have confidence that the undisturbed conditions have been adequately characterised both spatially and temporally. This data will further serve as background information for monitoring during other lifecycle phases of the deep geological repository.

\section{CREATION OF THE MODEL}

For evaluation of long-term safety of the deep geological repository the conceptual model of such a facility was developed. Main part of the model is reference biosphere, which is developed based on the BIOMASS methodology (IAEA, 1996). The role of the BIOMASS document is to provide a methodology in the process of creating practical examples demonstrating ways in which models of the biosphere for longterm safety assessment can be developed and appropriately assessed for the specific purposes. A relatively simple interface between the geosphere and the biosphere considers the natural flow of contaminated groundwater into the aquifer. This water passes through other transport pathways and then it is discharged into the surface. The ultimate goal is to calculate the effective dose for the individual without considering the evolution of the biosphere system [3].

\section{A. Disposal system and geosphere}

The modelled disposal system is based on a multi-barrier concept, which consists of a combination of engineering and natural barriers providing sufficient protection for the environment and the population over a very long period of time. All individual elements of the multi-barrier protection system are interacting with each other in such a way to isolate radionuclides from the biosphere. One of the barriers is the 
waste itself - very form of spent nuclear fuel. Another important barrier is disposal container inspired by Czech proposal, where spent fuel assemblies (from VVER-440 reactors) are considered to be disposed in. The disposal capacity of one container is 7 fuel assemblies. This container is constructed of stainless steel (inner part) and carbon steel (outer part) with an outer diameter of $650 \mathrm{~mm}$ and a length of $3670 \mathrm{~mm}$. Fuel assemblies are inserted into the inner profiled pipes made of aluminium alloy [4].

Within this assessment the calculations were performed for the spent fuel with an initial average enrichment of $4.25 \%$ of U-235 and burnup $60 \mathrm{MWd} / \mathrm{kgU}$. The calculations of spent nuclear fuel inventory was performed for the radial profiled VVER-440 fuel assembly of the 2nd generation by using the depletion module TRITON included in SCALE 6.1.3 code system. The model is 2D assembly model developed at our institute [5]. The time of storage before the final disposal was set at 50 years. Disposal container is surrounded by a bentonite buffer with a wall thickness of $300 \mathrm{~mm}$.

It is considered, that the disposal container fails due to normal evolution processes after 1000 years and water comes into contact with the source term (fuel and structural material), released radionuclides start to migrate through the repository system. After the radionuclides penetrate all the barriers in the near field represented by the spent nuclear fuel matrix itself, the disposal container, bentonite buffer and excavation disturbed zone (EDZ) they reach the geosphere. In our model, the geosphere is represented by a crystalline host rock environment where radionuclides reach the geospheres through the fractures and faults. The interconnection of the geosphere with the biosphere is represented by an aquifer, from which the contaminated water flows through the surface flow into the water reservoir.

\section{B. Reference biosphere}

The biosphere in this model is represented by a set of interconnected biosphere objects. A biosphere object is defined as an area of the landscape that can receive radionuclides released, either through discharge of deep groundwater or in contaminated surface water, at any time.

The primary medium through which radionuclides come into the biosphere is water. Contaminated water from the considered water reservoir is used as drinking water for the population, water for livestock and also for irrigation of the agricultural land. In this water reservoir also, fish are being farmed. On such land are cultivated cereals, vegetables, grassland and trees. Radionuclides are transported through the root or leaf system into the plants, hence either directly into the human organism, or into the animal organism from which the animal products enter the human body. Receiving of the radionuclides is also partially caused by the consumption of contaminated fish meat.

For livestock in our model, we consider bovine animals whose animal products - meat and milk are consumed by residents from the critical exposure group. In the process of creating a reference biosphere, some input elements were selected, representing the constituent elements of the environment within the biosphere model. In the case of crops, cereals, grassland and trees are considered in the model.

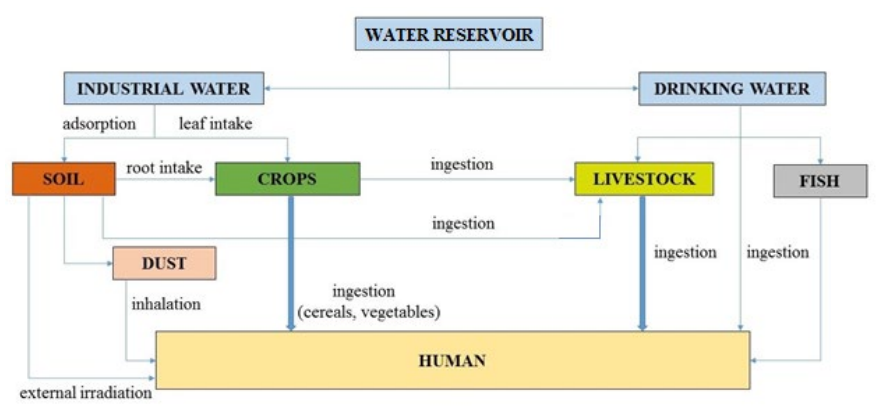

Fig. 2. Scheme of the conceptual model of the reference biosphere.

In the case of crops, cereals, grassland and trees are considered in the model. The schema of the conceptual model of biosphere and exposure pathways is shown in Fig. 2. Conservatively, it is assumed that all consumed environmental components are contaminated with radionuclides, with the primary exposure pathways such as ingestion, inhalation and external exposure.

We consider, that the source of an external exposure is contaminated soil. On the surface of the soil farmers are moved carrying out, for example, agricultural work. The value of the effective dose from external exposure is therefore dependent on the time spent on the contaminated soil. The exposure pathway of external exposure also includes external irradiation of the person's skin from the dust that is deposited on it.

The effective dose caused by inhalation depends, inter alia, on the amount of inhaled dust arising from the contaminated soil and the respiration rate of the exposed object, assuming a constant content of soil particles in the air. The exposure is caused by inhalation of particles of contaminated dust. The effective dose caused by ingestion depends on the amount of ingested contaminated water and contaminated food. The model for long-term safety assessment of the deep geological repository was developed using the GoldSim simulation tool [6].

\section{TRANSPORT CHARACTERISTICS IN BIOSPHERE}

Radionuclide transport processes included to the model are diffusion and sorption in the repository near-field and advection, matrix diffusion and sorption in the geosphere. A simplified approach to handle solubility limited release of the nuclide from the waste canister is also included into the model.

To assess radiological risks, the annual individual effective dose for an individual from a critical exposure group has been calculated. This value can be related to the risk of damage to health caused by ionizing radiation. For this purpose, a generally accepted method of calculating the radiation dose based on differential equation is used, the results of which determine the concentrations of individual radionuclides in the environmental components (crops, animal products, etc.) based on known, respectively calculated values of individual radionuclide concentrations in water and agricultural soil. For these calculations so-called concentration and translocation factors are used. These factors determine the transport of contaminants from soil and water into plants, respectively from plants consumed by livestock to animal products. 


\section{A. Definition of selected parameters}

Within the model, changes were made to selected parameters within the geosphere and biosphere. The selected parameters are diffusion coefficients for different soil types and translocation factors for selected environmental components.

\section{1) Distribution coefficients}

Sorption is the process, where dissolved contaminants partition from the ground-water and adhere to the particles of the bentonite and host rock matrix. Sorption of the dissolved radionuclides onto the matrix results in slowing (retardation) of contaminants relative to the average advective ground-water flow velocity and a reduction in dissolved concentrations in ground water.

The rate of sorption is described by distribution coefficient $\mathrm{K}_{\mathrm{d}}$, which is defined as the ratio of the sorbed contaminant concentration to the dissolved contaminant concentration. For systems described by a linear isotherm, $\mathrm{K}_{\mathrm{d}}$ is a constant [7].

$$
K_{d}=\frac{m_{s} / M_{s}}{m_{f} / V_{f}}
$$

where: $K_{d}$ - distribution coefficient $\left(\mathrm{m}^{3} / \mathrm{kg}\right)$,

$\mathrm{ms}$ - weight of the nuclide sorbed on the solid material $(\mathrm{kg})$,

Ms - weight of the solid material $(\mathrm{kg})$,

$\mathrm{mf}$ - weight of the nuclide dissolved in the liquid medium $(\mathrm{kg})$,

Vf - volume of the liquid medium $\left(\mathrm{m}^{3}\right)$.

Dissolved radionuclide ions can bind to solid surfaces by a number of processes that are often classified under the broad term of sorption. The behaviour and ultimate radiological impacts of radionuclides in soils are largely controlled by their chemical form and speciation, which strongly affect their mobility, the residence time within the soil rooting zone and uptake by biota.

The degree of radionuclide sorption on the solid phase is often quantified using the solid-liquid distribution coefficient, $\mathrm{K}_{\mathrm{d}}$, which can be used when making assessments of the overall mobility and likely residence times of radionuclides in soils. $\mathrm{K}_{\mathrm{d}}$ is the ratio of the concentration of radionuclide sorbed on a specified solid phase to the radionuclide concentration in a specified liquid phase, as describes following equation:

$K_{d}=\frac{\text { activity concentration in solid phase }[\mathrm{Bq} / \mathrm{kg}]}{\text { activity concentration in liquid phase }[\mathrm{Bq} / \mathrm{ll}]}$

The $K_{d}$ approach takes no explicit account of sorption mechanisms but assumes that the radionuclide on the solid phase is in equilibrium with the radionuclide in solution and that exchange between these phases is reversible.

\section{2) Translocation factors}

For the purpose to assess the radiological risks, the annual individual effective dose for an individual from a critical exposure group needs to be calculated. For doing so, a generally accepted method of calculating the radiation dose based on differential equation is used, the results of which determine the concentrations of individual radionuclides in the environmental components (crops, animal products, etc.) based on known, respectively calculated values of individual radionuclide concentrations in water and agricultural soil. For these calculations so-called concentration and translocation factors are used. These factors determine the transport of contaminants from soil and water into plants, respectively from plants consumed by livestock to animal products.

Radionuclide concentration in vegetables and cereals is calculated as follows [8]:

$C_{f o o d}=\left(C F_{f o o d}+\left(1-f_{\text {pregp }}\right) * s_{f \circ o d}\right) * C_{\text {soil }}+\mu_{f \circ o d} * q_{\text {irr }} * C_{\text {wrater }} * \frac{1-f_{\text {prep }}+f_{\text {trans }}}{Y_{\text {food }} * \lambda_{\text {weather }}}$

where:

$\mathrm{CF}_{\text {food }}[-]$ is a concentration factor for vegetables and cereals,

$\mathrm{f}_{\text {prep }}[-]$ is an external contamination loss due to processing,

$\mathrm{S}_{\text {food }}[\mathrm{kg} / \mathrm{kg}]$ is crop contamination by soil,

$\mathrm{C}_{\text {soil }} \quad\left[\mathrm{Bq} / \mathrm{m}^{3}\right]$

or $[\mathrm{Bq} / \mathrm{kg}]$ is soil concentration of radionuclide in soil,

$\mu_{\text {food }}[-]$ is fraction of contamination caused by irrigation,

qirr $\quad[\mathrm{mm} / \mathrm{year}]$ is amount of irrigation water,

$\mathrm{C}_{\text {water }}[\mathrm{Bq} / \mathrm{kg}]$ concentration of radionuclides in kilogram, resp. litters of water,

$f_{\text {trans }}[-]$ is fraction of activity passing from the surface to the interior of the plant,

$Y_{\text {food }}\left[\mathrm{kg} / \mathrm{m}^{2}\right]$ is crop yield,

$\lambda_{\text {weather }}[\mathrm{d} / \mathrm{kg}]$ is contamination loss coefficient due to weathering.

\section{B. Relationship between Kd and other parameters} characterizing radionuclide mobility

In a porous medium such as soil, the radionuclide diffusion process differs from diffusion in free water. Also, the ability of radionuclides to be sorbed onto porous media such as soil is different than for host rock itself. This feature is defined by the so-called retardation factor, which is defined as follows.

$$
f_{\text {ret }}=1+\left(\frac{\rho}{\varepsilon}\right) \cdot K_{d}
$$

where: $f_{\text {ret }}$ - retardation factor (-),

$\rho$ - dry bulk density of the soil $\left(\mathrm{kg} / \mathrm{m}^{3}\right)$,

$\varepsilon$ - total porosity of the medium,

$\mathrm{Kd}$ - distribution coefficient $\left(\mathrm{m}^{3} / \mathrm{kg}\right)$.

It determines what amount of radionuclide is bound to the medium during the migration process and how much of it will be transported further. Radionuclides are transported from the soil to the roots of plants and other parts of the environmental components from where they either directly or indirectly enter the human body.

\section{EXPOSURE ASSESSMENT FOR CONSIDERED SCENARIOS}

In order to evaluate the long-term safety of the deep geological disposal system of spent nuclear fuel, our aim was to determine the values of the annual effective doses for individuals from the critical exposure group for considered 
deep geological repository. The representative individual from a critical exposure group is considered to be an adult person (over the age of 17 years). The geosphere and the disposal system, where disposal containers for spent nuclear fuel are considered to be disposed in and sealing material (bentonite), are modelled conservatively. The scenario is based on the National Program for Spent Nuclear Fuel and Radioactive Waste Management in Slovak Republic [9], which requires the allocation of 32658 spent nuclear fuel assemblies produced from the 60-year operation of Slovak nuclear power plants in the repository. Since it is assumed that the capacity of one disposal container is 7 fuel assemblies, we assume that approximately 4666 containers will be disposed in the deep geological repository. The conservative scenario further assumes that each disposal container will fail after 1000 years due to degradation of the materials used in repository.

It is assumed that the main transport pathway of radionuclide migration is groundwater, which passes through fractures and faults in the geosphere and into the aquifer and then to the water reservoir. Radionuclide transport processes included into the model are diffusion and sorption in the repository near-field and advection, matrix diffusion and sorption in the geosphere. Contamination of the environmental media is caused by the transport of released radionuclides from the source term and is significantly dependent on the defined boundary conditions of the initial reachable parts of the biosphere.

For each disposal container, same boundary conditions are assumed (same container distance from host rock fractures, the same transport pathway of released radionuclides etc.). The chosen scenario for assessing the long-term safety of the deep geological repository considers a normal evolution scenario. It is based on the assumption that the conditions for which the repository was built are unchanged throughout its whole existence and that the properties of engineering barriers correspond to project prerequisites. It is not considered the introspection of the person into the disposal area, the climatic conditions remains unchanged, the use of the environmental components associated with the agricultural activity and other activities is identical throughout the evaluated period to the current habits.

For purposes of our analysis, investigation of the impact of selected parameters changes on the long-term safety of the deep geological repository was performed. Selected parameters are diffusion coefficients for various soil types and transfer factors for selected environmental media (root and leafy plants, cereals and crops). Diffusion coefficient $\mathrm{K}_{\mathrm{d}}\left[\mathrm{m}^{3} / \mathrm{kg}\right]$ represents ability of radionuclide to be sorbed (retented) within the media. Transfer factors $t_{\mathrm{f}}[-]$ are defined as the ratio of the contaminant concentration in the plants and the concentration in the specific soil layer. Within the model, ingestion of selected crops is considered to be the dominant intake pathway. Distribution coefficients for various soil types and ingestion rate of selected environmental components can be seen from Table I. and Table II.
TABLE I. DISTRIBUTION COEFFICIENTS FOR VARIOUS SOIL TYPES [10]

\begin{tabular}{|c|c|c|c|}
\hline \multicolumn{5}{|c|}{ DISTRIBUTION COEFFICIENTS $\left[\mathbf{m}^{3} / \mathbf{k g}\right]$} \\
\hline ELEMENT & Loamy soil & Clay soil & Sand \\
\hline$A c$ & 47 & 24 & 2.77 \\
\hline$A m$ & 17 & 84 & 4.4 \\
\hline$C$ & 0.0007 & 0.09 & 0.0086 \\
\hline$C l$ & 7.3 & 20 & 0.014 \\
\hline$C m$ & 12.6 & 54 & 2.4 \\
\hline$C s$ & 0.46 & 1.9 & 0.029 \\
\hline$I$ & 0.004 & 0.01 & 0.0003 \\
\hline$N b$ & 15.6 & 92 & 5.1 \\
\hline$N p$ & 12.3 & 98 & 3.24 \\
\hline$P a$ & 4.7 & 27 & 10 \\
\hline$P b$ & 0.01 & 0.94 & 0.0074 \\
\hline$P d$ & 1.5 & 6.7 & 2.7 \\
\hline$P u$ & 1.4 & 3.6 & 0.86 \\
\hline$R a$ & 0.049 & 0.53 & 0.0038 \\
\hline$S e$ & 0.55 & 0.89 & 0.34 \\
\hline$S m$ & 2.9 & 11.1 & 6.1 \\
\hline$S n$ & 13 & 33 & 3 \\
\hline$T c$ & 12 & 18.2 & 4.8 \\
\hline$T h$ & 0.0018 & 0.028 & 0.00062 \\
\hline$U$ & 0.08 & 0.0441 & 0.0026 \\
\hline$Z r$ & 6 & 1.2 & 8.2 \\
\hline
\end{tabular}

TABLE II. INGESTION RATE OF SELECTED ENVIRONMENTAL COMPONENTS [11]

\begin{tabular}{|c|c|}
\hline & ADULTS (> 17 years) \\
\hline Milk and milk products [l/year] & 15.3 \\
\hline Meat [kg/year] & 6 \\
\hline Cereals [kg/year] & 157 \\
\hline Vegetables [kg/year] & 75 \\
\hline Crops [kg/year] & 43 \\
\hline
\end{tabular}

These different types of soil were chosen because of the fact, that all these soil types are present in prospective localities for the siting of the deep geological repository in Slovakia and therefore they may be the subject of further research in this area in the future. The higher the value of the respective distribution coefficient is, the more the given nuclide can be retarded within the engineering and natural barriers, the later it enters the environment and thus the more optimistic scenario is assumed. The rate of selected ingestion rate of selected environmental components was determined on the basis of data from the Statistical Office of the Slovak Republic.

\section{Result of the simulations}

The calculated maximal annual effective dose for representative individual from the critical exposure group shows Fig. 3. 


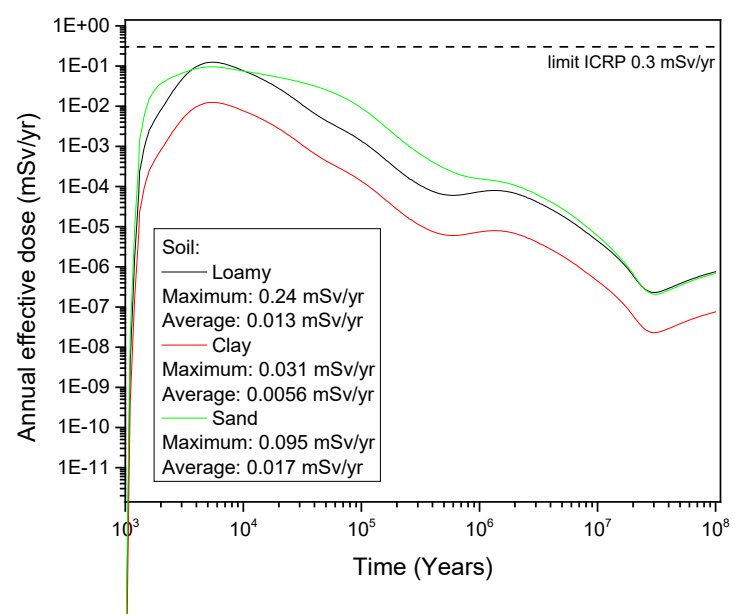

Fig. 3. Annual effective doses for selected changes in the model of deep geological repository.

From this figure, we can see that the maximal value of the annual effective dose was calculated for the loamy soil and the minimum value for the sand. Within these results it can be said, that the retardation factor depends significantly on the soil porosity and retention properties of the individual radionuclides. We can conclude, that from the dose point of view, the most important is the first achieved part of the biosphere, which is in our case represented by the soil. Changing translocation coefficients for individual soil types and selected environmental components has only a negligible effect on the calculated dose value.

Maximal values of achieved doses had been also compared to the limit established by the International Commission on Radiological Protection (ICRP) for waste disposal facilities. Radiological limits for the long-term assessment of the safety of a waste disposal facility recommended by ICRP is set to an annual dose constraint for the population of $0.3 \mathrm{mSv} /$ year [12]. The values of the maximum annual effective dose are in all considered cases lower than this limit.

In all the considered cases, the same radionuclides affect total annual effective dose. Contribution of selected radionuclides for an adult representative shows Fig. 4. The release rate of many nuclides is reduced due to the transport of nuclides through the host rock and the major water-conducting fault. Actinides are relatively strongly sorbed on the bentonite as well as on the host rock matrix and therefore their release rates are very low. The largest contribution to total annual effective dose represent activation and fission products C-14, Cl-36, I-129, Se-79 and Cs-135.

I-129 and Cl-36 are assumed to have very poor retentive properties and that's why these nuclides dominate the total release rate for a long period of time. In the early years, the most significant nuclide dominating the total release rate is C-14. It is caused by its relatively high specific activity in comparison with long-lived radionuclides.

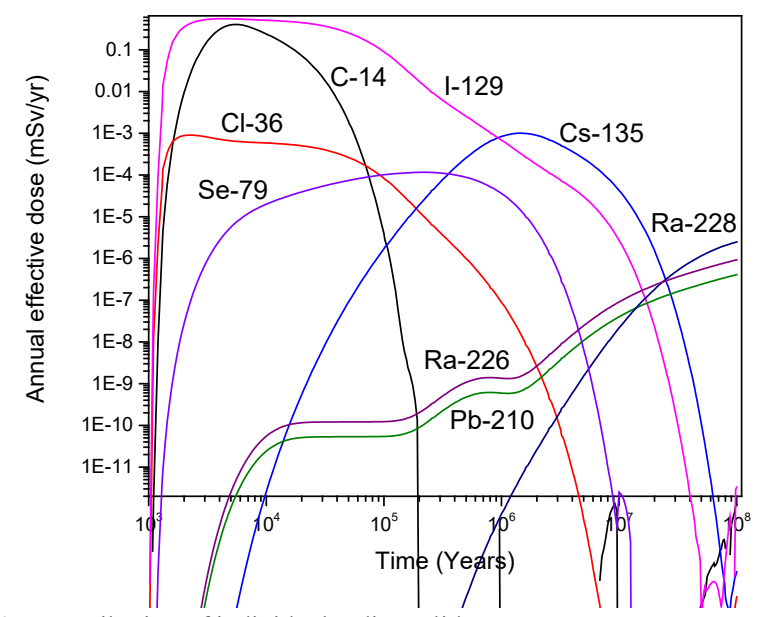

Fig. 4. Contribution of individual radionuclides.

In the last years of the analysis the increase in dose is due to the contribution of specific radionuclides. $\mathrm{Pb}-210$ accumulates in the soil at a later time of the analysis and from there passes into the plant leaves. The maximum far field dose from Ra-226 increases because of the greater amount of uranium in spent fuel. Ra-226 migrates appreciably from the repository system only as a result of the migration of Th-230, which is not at a high enough concentration to be solubility limited.

\section{CONCLUSION}

To evaluate the long-term safety of the deep geological repository, a model of the disposal system, geosphere and the initial model of the reference biosphere has been developed. Using the GoldSim simulation tool, the annual effective dose for individuals of different ages from critical exposure group was calculated. Within the analysis, the impact of changes in distribution coefficients for different soil types and relevant translocation factors expressing the rate of contaminant transition into environmental compartments was investigated, when ingestion is considered to the dominant exposure pathway. From the results we can see, that the properties of the first achieved part of the biosphere have a significant influence on the dose value. Subsequent changes in other contaminant spreading parameters have a negligible effect on the overall dose. The maximum dose value is in all cases lower than the recommended limit set by the ICRP. In all considered cases, same radionuclides affect annual effective dose. In the last years of the analysis the increase in dose is due to the contribution of specific radionuclides. $\mathrm{Pb}-210$ accumulates in the soil at a later time of the analysis and from there passes into the plant leaves. The maximum far field dose from Ra-226 increases because of the greater amount of uranium in spent fuel. Ra-226 migrates appreciably from the repository system only as a result of the migration of $\mathrm{Th}-230$, which is not at a high enough concentration to be solubility limited. 


\section{ACKNOWLEDGMENT}

This study has been partially supported by the Slovak Grant Agency for Sciences through grant VEGA 1/0863/17 and by the Slovak Research and Development Agency through grant APVV-15-0558.

\section{REFERENCES}

[1] M. Jobmann, „MODERN 2020,“ Second Technical Meeting of the Working Group on the Use of Monitoring Programme in the Safe Development of Geological Disposal Facilities for Radioactive Waste, Vienna, Austria, December 2018.

[2] OECD/NEA, ,Preservation of Records, Knowledge and Memory across Generations, Monitoring of Geological Disposal Facilities - Technical and Societal Aspects,“, February 2014, pp. 15-18.

[3] International Atomic Energy Agency (IAEA). „Reference Biospheres“ for Solid Radioactive Waste Disposal. Report of BIOMASS Theme 1 of the BIOsphere Modelling and ASSessment (BIOMASS) Programme," ISBN 92-0-106303-2, Vienna, Austria, 2003.

[4] Radioactive Waste Repository Authority, "Reference Project of Geological Repository: Technological Part,”. Czech Republic. 1999, pp. 50-55

[5] B. Vrban, J. Lüley, D. Barátová, J. Haščík, V. Nečas, "Parametric Study of Burnup Modelling Aspects of VVER-440/V213 Fuel," 26th International Conference Nuclear Energy for New Europe, Nuclear Society of Slovenia, Bled, Slovenia, September 2017.

[6] GoldSim Technology Group, LLC. GoldSim Contaminant Transport Module, User`s Guide. version 7.0., Washington, USA, 2017.

[7] V. M. Pulkkanen, H. Nordman, "Modelling of Near-Field Radionuclide Transport Phenomena in a KBS-3V Type of Repository for Nuclear Waste with GoldSim Code - and Verification Against Previous Methods.”. Finland: Posiva Oy, March 2010, pp. 37.

[8] Nordén S. et. al., "Element-specific and constant parameters used for dose calculation in SR-Site", Svensk Kärnbränslehantering AB, Sweden, 2010.

[9] National Nuclear Fund for Decommissioning of Nuclear Facilities and for the Management of Spent Nuclear Fuel and Radioactive Waste, "National Program for Spent Nuclear Fuel and Radioactive Waste Management in Slovak Republic,”, Slovak Republic, August 2014.

[10] International Atomic Energy Agency (IAEA). Technical Report Series no, 472., "Handbook of Parameter Values for the Prediction of Radionuclide Transfer in Terrestrial and Freshwater Environments," ISBN 978-92-0-113009-9, Vienna, Austria, 2010, pp. 42-62.

[11] Statistical Office of Slovak Republic, 2017.

[12] Annals of the ICRP, ICRP Publication 122, "Radiological Protection in Geological Disposal of Long-lived Solid Radioactive Waste,”. 2013, pp. 14. 